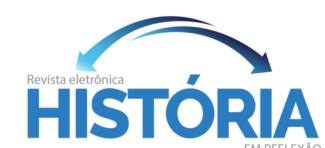

A POSSE DE TERRAS NO OESTE COLONIAL SETECENTISTA: SESMARIAS E MULHERES EM MATO GROSSO

Bruno C. Bio Augusto \& Oseias de Oliveira

\title{
A POSSE DE TERRAS NO OESTE COLONIAL SETECENTISTA: SESMARIAS E MULHERES EM MATO GROSSO
}

\section{LAND TENURE IN THE COLONIAL WEST SEVENTEENTH: SESMARIAS AND WOMEN IN MATO GROSSO}

Bruno C. Bio Augusto ${ }^{1}$

Oseias de Oliveira ${ }^{2}$

\begin{abstract}
Resumo: Este trabalho compreende o cotidiano rural da Capitânia de Mato Grosso, ao longo do século XVIII, a partir da ocupação de terras. Entende também a preocupação da Coroa em fortalecer as fronteiras coloniais pela legitimação de posses. No suporte documental, vamos utilizar fontes adquiridas no Arquivo Público de Mato Grosso, como o "Requerimento de Teodora Paes de Faria para o Governador João Albuquerque de Melo Pereira e Cáceres", de 1791. As sesmarias trabalhadas neste artigo estavam nas mãos de mulheres, ou seja, a história contada será protagonizada pelas donas mineiras e que possibilitam entender táticas cotidianas para manter o controle de suas propriedades.
\end{abstract}

Palavras Chave: Mulheres; Colônia; Mato Grosso.

Abstract: This work comprises the rural daily life of the Captaincy of Mato Grosso, throughout the eighteenth century, from the occupation of lands. It also understands the Crown's concern to strengthen colonial frontiers by legitimizing possessions. In documentary support, we will use sources acquired in the Public Archive of Mato Grosso, such as the "Request of Teodora Paes de Faria for Governor João Albuquerque de Melo Pereira and Cáceres", 1791. The sesmarias worked in this article were in the hands of women, that is, the story told will be carried out by the donas of Minas Gerais and that they can understand daily tactics to keep control of their properties.

Key-Words: Women; Colonial; Mato Grosso.

INTRODUÇÃO

Para este trabalho, o Arquivo Público de Mato Grosso, cidade de Cuiabá, foi de suma importância. O manejo com as fontes busca o "não-dito" postulado nas

Mestrando do Programa de Pós-Graduação em História da Universidade Estadual do Centro-

Oeste do Paraná (Unicentro-Irati). Bolsista Capes.

2 Profo Dr. do Programa de Pós-Graduação em História da Universidade Estadual do Centro-Oeste do Paraná (Unicentro-Irati). 


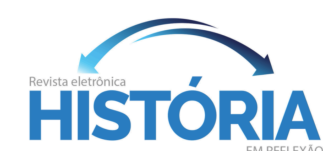

A POSSE DE TERRAS NO OESTE COLONIAL SETECENTISTA: SESMARIAS E MULHERES EM MATO GROSSO

Bruno C. Bio Augusto \& Oseias de Oliveira

subjetividades dos arquivos e torna imprescindível para entendermos a construção do mundo social colonial. Quando não encontrada diretamente a protagonização das mulheres, o(a) pesquisador(a) precisa estar atento(a) para ruídos do cotidiano feminino, pois escrita é ferramenta do(a) historiador(a) que: "simboliza uma sociedade capaz de gerir o espaço que ela se dá, de substituir a obscuridade do corpo vivido pelo enunciado" (CERTEAU, 1982, p.17).

Para formar propriedade de terras é preciso que haja relações de poder entre os indivíduos. São nestas relações que se encontra a fronteira, seja ela física ou subjetiva. Portanto, para compreendermos a posse da terra e sua conquista, na qual a unidade de produção rural poderia ser adquirida de várias maneiras: matrimônio, compadrio, amizade, acordos jurídicos, entre outras situações. Então, para o manejar da lupa do(a) historiador(a), é preciso uma leitura minuciosa dos documentos (LEFEBVRE, 2000).

Estudarmos o cenário cuiabano do século XVIII nas propriedades rurais é apreender aspectos da vida administrativa e econômica da ocupação do Oeste colonial. Ao longo dos Setecentos, Mato Grosso, por ser região de fronteira com a América Espanhola, participou de projetos com tratados no intuito de definir as posses entre Espanha e Portugal. Portanto, faz-se necessário compreender como o "sertão" aparecia na compreensão da época e, para isso, analisar estudos acerca do espaço, região e fronteira. Uma tríade importante na história de Mato Grosso Colonial.

Para Amado (1995), a categoria 'sertão' está presente na história do Brasil desde a sua ocupação, no século XVI. Aparece nas literaturas da época das conquistas como ambiente incivilizado, marcado pela barbárie. O sertão era o oposto do litoral. Dizendo melhor, no litoral, representado pelos centros urbanos de Salvador e Rio de Janeiro, estava o modelo de civilização. Era necessário para esse período, portanto, tirar a bravidade, ou seja, desbravar o interior da América portuguesa e civilizar aquela gente.

O sertão é entendido pela historiografia como uma representação do espaço social. De acordo com Lefebvre (2000), o espaço é um elemento social que compreende a prática de quem o habita; e os grupos sociais apropriam, produz e reproduz o espaço social praticado. O espaço, pela prática de seus sujeitos, é marcado pelo conflito, ou seja, pela disputa de poder. 


\section{HISTÓRIA \\ A POSSE DE TERRAS NO OESTE COLONIAL SETECENTISTA: SESMARIAS E MULHERES EM MATO GROSSO \\ Bruno C. Bio Augusto \& Oseias de Oliveira}

A capitânia de Mato Grosso, por estar associado ao contexto fronteiriço, apresenta nas documentações indagadas nesta pesquisa a preocupação da Coroa em fortificar e proteger os territórios das posses meridionais dos vizinhos castelhanos. Por isso, é importante contextualizarmos as políticas de uso da terra.

Primeiras ocupações das regiões auríferas do rio Cuyabá

Ambientes de fronteiras apresentam a interação entre diferentes grupos sociais como, por exemplo, sesmeiros e posseiros; ou pela solidariedade de grupos, como no caso dos aquilombados. A partir da ideia de Martins (1997) para o entendimento das fronteiras, compreendemos que Mato Grosso apresentou em sua história uma inserção social de conflitualidade entre vários aspectos: o poder do Estado e o poder da elite local, que muitas vezes entravam em desconsoantes disputas; os conflitos entre marcos, físicos e ideológicos, da América lusa e América hispânica; as guerras justas; a caça pelos quilombolas, enfim, Mato Grosso Setecentista representou espaços múltiplos e de disputa pela ocupação da terra (MARTINS, 1997).

Para Certeau (1998), os espaços são formados pelas práticas cotidianos dos sujeitos que neles estão inseridos. Assim, é um conjunto de movimentos construídos pelas operações que orientam e temporalizam ações de conflitos. Há sempre conflitos acontecendo no espaço e eles são criados a partir das ações dos indivíduos. Para Certeau (1998), estas ações são conhecidas como 'relatos' e estão dotadas de sentidos, ou seja, de percepções de quem relata algo.

Estes relatos têm limites, e, muitas vezes, esses limites são representados pela fronteira. A fronteira não precisa ser física. Quando encontramos, no caso de nossa pesquisa, regras para a ocupação de terras, concessão de sesmarias, recebimento de heranças, estamos lidando com fronteira: o limite da racionalização pelo Estado. Portanto, ao construirmos a história de Mato Grosso, os marcos físicos entre América espanhola e portuguesa são importantes, mas também há, subsumida na atuação dos moradores daquela capitania, os limites de direitos e deveres subjetivos.

No ano de 1717, o conde de Assumar enviou uma carta ao rei na qual relata o encontro de ouro nas encostas do rio Paraguai; na década posterior, há relatos de ouro no rio Cuiabá (CANAVARROS, 2004). Assim, nas décadas de 1720 e 1730, 


\section{HISTÓRIA \\ A POSSE DE TERRAS NO OESTE COLONIAL SETECENTISTA: SESMARIAS E MULHERES EM MATO GROSSO \\ Bruno C. Bio Augusto \& Oseias de Oliveira}

houve um período auspicioso de riqueza para a Coroa portuguesa oriundo do extrativismo aurífero de Cuiabá. Foi também um período marcado por movimentações internas de pessoas, como nos relata o cronista Barbosa de Sá que: "ao ser divulgada a notícia da descoberta do ouro nos sertões do Cuiabá, as esperanças da América Portuguesa e de sua metrópole foram realimentadas" (JESUS, 2001 p.23).

Esse período é propício para o surgimento de navegações pelos rios que interligam São Paulo ao norte da capitânia, na primeira metade do século XVIII, e, posteriormente, há a abertura de caminhos terrestres, mostrando-nos a necessidade da administração colonial em fincar pousos para os viajantes e postos de fiscalização de produtos que entravam e saiam da região. Assim, segundo Fragoso et al. (1998), cria-se uma rede de negociações que abraça o oeste da América portuguesa.

Destarte, vemos a preocupação também de controlar o acesso de mulheres de estado "duvidoso" no vai e vem das minas cuiabanas:

Ordeno, e mando, q' nenhûa pessoa de qualquer estado, e condição q' seja, possa levar em sua companhia, $p^{a}$ as ditas minas nenhûa mulher branca de suspeita bastarda, ou Mulata forra, debaixo de pena de pagarem por cada húa q' levarem ou lhe for achado em sua companhia, trezentos mil r.s (GOVERNADOR GENERAL RODRIGO CEZAR DE MENEZES, 1727).

Nesse contexto de multas, imersos nas relações sociais que integravam o modo de vida das mulheres pobres e abastadas da sociedade colonial, há indícios de atritos encontrados nos documentos. Assim, explicitamos a intimidade do público e do privado mineiro cuiabano, em especial, na referência às personagens que estavam à margem da economia aurífera: as mulheres.

Ao mesmo tempo que fechava a região para alguns sujeitos, especialmente pobres e "desclassificados", tornando-os ilegais aos olhos da administração lusitana, a Coroa abria espaço para a ocupação demográfica. Como no ano de 1751, em que o Conde de Azambuja mandava uma carta de 2 de julho ao Diogo Mendonça:

$\mathrm{Na}$ Instrução que Sua Majestade foi servido mandar-me dar quando vim para este Governo se me ordena considere os mais privilégios e isenções que sem inconveniente poderão acrescentar-se para convidar moradores e mineiros a irem povoar o território de Mato Grosso (NÚCLEO DE DOCUMENTAÇÃO, 1982 p.36).

Para o contexto do controle da riqueza aurífera, com o medo do extravio do ouro devido ao fluxo de pessoas na região das minas, a Coroa criou casas de fundição 


\section{HISTÓRIA \\ A POSSE DE TERRAS NO OESTE COLONIAL SETECENTISTA: SESMARIAS E MULHERES EM MATO GROSSO \\ Bruno C. Bio Augusto \& Oseias de Oliveira}

para quintar o ouro. Em uma carta de Rodrigo Cezar de Menezes, escrita em 28 de março de 1728, na qual expõe: "da chegada das ultimas canoas q. foraõ destas Minas para povoado com o avizo de que já a Casa de fundiçaõ estava estabelecida e com exercicio" (MORGADO, 2007. MF. 06, Doc. 80, AHU).

O governador utilizava da cobrança de "quintos por bateyas", enquanto a casa de fundição não fosse estabelecida nas regiões auríferas e, para aumentar o lucro da Coroa, a política de Rodrigo Cezar de Menezes, nos anos iniciais da fundação da Vila de Nosso Senhor Bom Jesus do Cuyabá, foi acrescentar uma oitava, anualmente, aos impostos:

[...] em falta deste, mandey proceder ao lançamento do Quintos por Bateya, como nestas minas tinha estabelecido, sendo este aconseritim. ${ }^{\text {to }}$ do Povo, e o conseguy felizmente com aumento de hua oytava mais . $^{\text {a }}$ a real Fazenda, passando de seis, a sette, e nos annos seguinte cresceria mais (COSENTINO, 2011, p.01).

Neste contexto, Fragoso (2009) discorre sobre a relação régia dos dois polos da governança: a Metrópole e sua extensão, ou seja, suas colônias.

Nela [monarquia pluricontinental] há um só reino - o de Portugal -, uma só nobreza de sola, mas também diversas conquistas extraeuropéias. [...] Tratava-se, na verdade, na América lusa, por exemplo, de poderes locais - no limite, se organizaram enquanto capitanias que tomavam instituições sócio organizacionais reinóis como referências para a formalização de sua sociedade colonial autônoma. (FRAGOSO, 2009 p.42-43)

As colônias do além-mar eram importantes para manutenção dos cargos régios e, principalmente, captação financeira das riquezas tropicais. Em um documento de Marquês de Pombal, da segunda metade do século XVIII, compreendemos as medidas para Portugal continuar usufruindo da mineração colonial:

Esse importantissimo, e instantissimo negocio [mineração] me parece que senão pode decidir, há ao mesmo tempo os tres objectos seguintes:

Primeiro objecto: conservamos as Minas; deforte, que não declinem do Estado prezente:

Segundo objecto: Promovermos autil, e officioza cobiça dos Mineiros, para que cada dia se animem amayores serviçoes e a mais vastos descubrimentos:

Terceiro objecto: Ellegermos entre os muitos methodos, que fetem [sic] praticado atê agora, aquelle que pareces mais proprio para fazer entrar nos cofres de El Rey N. S. os Guintos, que são dividos a S. Mag, com o menos descaminho (POMBAL, 1750). 


\section{HISTORIA \\ A POSSE DE TERRAS NO OESTE COLONIAL SETECENTISTA: SESMARIAS E MULHERES EM MATO GROSSO \\ Bruno C. Bio Augusto \& Oseias de Oliveira}

Assim, a Coroa portuguesa foi criando meios para fiscalizar e instaurar nas minas uma extensão das régias administrativas metropolitanas. Taticamente ao promover a "officioza cobiça dos Mineiros", induzia-se a mobilidade social e o jogo de poderes na rede de relações coloniais. Conforme fonte acima, os representantes da Coroa nas minas seriam empregados por subsídios do rei em viagens no intuito de "desbravar" as localidades dos "certões", em que: "no mais interior do Certaõ, de todo o Estado do Brazil do seo estabelecim. ${ }^{\text {to }}$, povoaçaõ, e aumento, se seguem mayor producto, a Fazenda Real, e mais larga extençaõ do Domínio da Coroa, naquelles dezertos, ainda indecizos pella linha imagiinaria" (MORGADO, 2007. MF. 06, Doc. 80, AHU). E, neste cotexto, a terra se tornou importante instrumento de posse para fixar os habitantes na região, bem como produzir alimentos em terras do ouro.

O Tratado de Madri, assinado em 1750, mostra a preocupação da Coroa em delimitar e fixar marcos territoriais a respeito de suas posses. De acordo com Moraes (2011), esse acordo entre Portugal e Espanha fez uso do uti possidetis, ou seja, as terras eram por direito da nação que já a ocupava. A capitania de Mato Grosso foi, de acordo com este autor, uma estratégia lusa para dilatar suas posses e definir, diplomaticamente, a fronteira.

O Tratado de Madri não foi a única regulamentação para acertar as questões de fronteiras. A história mato-grossense contou com vários outros acordos e tão pouco foram eficazes para delimitar as terras. Em seguida, vamos trabalhar com a política da ocupação das terras pelos civis e, consequentemente, entender o papel do campesinato na construção colonial.

Campesinato e a posse da terra em Mato Grosso Setecentistas pelas mulheres

Em Mato Grosso, a política de concessão de terras foi estabelecida com o objetivo de ocupar a região. Geograficamente, a capitania de Mato Grosso estava dividida em duas repartições: a do Cuiabá, e a do Mato Grosso. Para Silva (2008), analisar a política de ocupação territorial da capitania de Mato Grosso por meio dos processos de concessão é entender as implicações, desentendimentos e disputas entre colonos e Coroa e, também, entre os próprios colonos. 


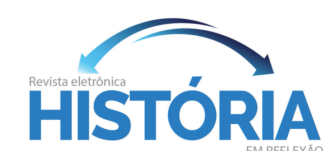

A POSSE DE TERRAS NO OESTE COLONIAL SETECENTISTA: SESMARIAS E MULHERES EM MATO GROSSO

Bruno C. Bio Augusto \& Oseias de Oliveira

A lei de sesmarias surge em Portugal no ano de 1375 durante o reinado de D. Fernando. Essa lei foi criada com intentos de solucionar problemas agrários e de produção daquele país. Integraram às Ordenações Afonsinas (1446), Manuelinas (1521) e Filipinas (1603). A implantação dessa prática na Colônia contou por séries de adaptações de leis esparsas que buscavam atender o processo de colonização (SILVA, 2008).

Durante o período colonial mato grossense, os governadores e capitães generais mostraram preocupados com o controle a respeito da ocupação das terras. Silva (2008) expressa que, ao chegar à capitania, em 1751, o primeiro governador de Mato Grosso - pois até 1748 a porção de terras pertencia à Capitania de São Paulo -, Antônio Rolim de Moura, lançou vários bandos que procuravam regulamentar a posse das terras.

Segundo Rolim de Moura, ao chegar nas minas, maior parte dos morados possuíam terras sem carta de sesmarias e, indo de contramão à legislação, era proibido as vendas. Mas, mesmo assim, o governador encontrou a prática de vendas e repartições. Rolim de Moura expressou a desobediência dos moradores para as ordens e autoridades régias daquele local (SILVA, 2008).

Posteriormente, no ano de 1773, o então governador Luis de Albuquerque de Melo Pereira e Cáceres publicou um bando enfatizando a importância de estabelecer roças nas regiões auríferas, a fim de garantir o abastecimento local. No ano de 1789 , o mesmo governador escreveu ao rei informando a dificuldade em responder os pedidos de sesmarias. O problema, de acordo com o governador, estava na falta de registros dos sesmeiros nas Câmaras Municipais (SILVA, 2008).

Para a história social da agricultura, principalmente após os estudos do protocampesinato, pesquisado por Ciro Flamarion Cardoso, compreendeu-se que a época colonial não foi marcada apenas pelos ciclos econômicos da cana, ouro e café para enriquecer a metrópole. Cardoso, de acordo com Linhares \& Da Silva (1981), contribuiu para a historiografia ao afirmar que as pequenas roças de alimentos, muitas vezes estabelecidas ao lado da monocultura, instigavam o comércio local e alimentavam a população.

Segundo Gomes (2008), na história social da agricultura foram diversos enfoques acerca da temática de produção de alimento. Dessa maneira, ainda para 
A POSSE DE TERRAS NO OESTE COLONIAL SETECENTISTA: SESMARIAS E MULHERES EM MATO GROSSO

Bruno C. Bio Augusto \& Oseias de Oliveira

esta autora, foram pesquisados as alternâncias populacionais a partir das crises de fome, as rebeliões relacionadas com a falta de alimentos e também a adaptação da produção agrícola com o meio físico.

As "práticas alimentares" são identificadas a partir da concepção de gênero comestível, as diferentes formas de sua apropriação, preparar, servir e consumir os alimentos. Dessa maneira, alimentar-se não é apenas um ato nutricional, é um ato social que obedece códigos e símbolos ligados aos costumes, condutas e situação (GOMES, 2008).

A prática das monções, ao menos nas rotas entre São Paulo e Cuiabá, pelo rio Tiete, rio Grande, rio Paraguai e o rio Cuiabá, bem como por outros trajetos, foram marcadas pela presença de roças. Na América portuguesa era costumes os viajantes cultivarem áreas com milhos, abóboras, e outros alimentos, no intuito de amenizar as intempéries das viagens que duravam meses pelos rios. Ao longo do século XVIII, foram constituindo pontos de abastecimentos alimentares nos trajetos monçoeiros, como no caso de Camapuã, que tornaria uma importante fazenda de alimentos para o comércio dos viajantes com destino à Cuiabá (GOMES, 2008).

De acordo com Gomes (2008), pelo relato do governador Rolim de Moura, de 1751, além das plantações, a natureza oferecia produtos de caça, pesca e frutos como laranjas, palmitos, castanhas e bananas.

Após a segunda metade do século XVIII, a capitânia de Mato Grosso contava com uma paisagem agrícola articulado com o projeto de expansão fronteiriço. As ocupações mato-grossenses, acompanhadas pelas assinaturas de Tratados, vão produzindo ambientes marcados por sesmarias, roças e núcleos urbanos (OLIVEIRA, 2008).

As terras de Mato Grosso, especialmente em Vila do Cuiabá, vinham sendo ocupadas desde o começo do século XVIII, mas foi apenas em 1726, com a vinda do governador de São Paulo à região, que as posses obtiveram legitimidades por meio de cartas de sesmarias. A primeira carta de sesmarias que concedia terras em Vila do Cuiabá teve como beneficiado o tenente-coronel Antonio de Almeida Lara. A concessão foi de duas léguas em quadra e, destas, uma seria para o cultivo de gêneros agrícolas (OLIVEIRA, 2008). 
A POSSE DE TERRAS NO OESTE COLONIAL SETECENTISTA: SESMARIAS E MULHERES EM MATO GROSSO

Bruno C. Bio Augusto \& Oseias de Oliveira

A busca pelas mulheres nas fontes não é um trabalho fácil para o(a) historiador(a). Muitas vezes o feminino está subsumido pela figura masculina e por assuntos masculinizados do cotidiano da vida na Colônia. Portanto, o ofício de recontar o contexto da documentação exige esforço, sensibilidade, e compreensão que possibilite imaginarmos o dia a dia daquele período (PERROT, 2005).

Dessa forma, qual o papel das mulheres no espaço colonial em uma sociedade marcada pela masculinização das práticas sociais? Mulheres obtinham acesso às terras naquele período? Quais as práticas cotidianas, de acordo com a documentação, realizadas pelas mulheres para a manutenção de sua terra? Estas são algumas das indagações que, provavelmente, responderemos neste trabalho.

Incorporar a história das mulheres e sua relação com a terra em Mato Grosso, proporcionando uma historicidade do feminino, está associado à práticas cotidianas dos(as) agentes sociais daquele período e de suas disputas pelos espaços. Significa entender a concepção do rural a partir da historiografia social brasileira que, até meados da década de 1960, compreendia o campo como um ambiente atrasado e com falta de infraestrutura. Herança, de acordo com esse modelo de pensamento, da rudimentar situação agrária do Brasil Colônia. Por outro lado, a historiografia, após a década de 1980, contou com a compreensão na qual a América portuguesa fora constituída por especificidades, ou seja, não podendo ser analisada com modelos hipotéticos generalizantes maniqueístas de atrasado e/ou modernizado. A história social da agricultura, neste período, entende que o(a) pequeno(a) camponês(a) também foi peça fundamental para a construção econômica e social do Brasil. As roças, vista com atraso até então, tinham papel importante para o abastecimento interno e eram estabelecidas ao lado da monocultura (MOTTA, 2014).

Estudar a presença e sobrevivência feminina em um cenário no qual há necessidade das mulheres se afirmarem e reafirmarem defronte ao contexto de possíveis domínios masculinos, proporciona ao historiador(a) apreender as legitimações do poder formal (régio) e as brechas que a informalidade proporciona aos marginalizados do sistema, tendo, com isso, a mulher como personagem social das ações cotidianas. Especialmente àquelas ligadas às práticas de atividades limitadas à vida doméstica, mas que, se observadas com atenção, é possível ver peculiaridades de suas conquistas no direito a usufruir a terra. Pois no cenário 


\section{HISTÓRIA \\ A POSSE DE TERRAS NO OESTE COLONIAL SETECENTISTA: SESMARIAS E MULHERES EM MATO GROSSO \\ Bruno C. Bio Augusto \& Oseias de Oliveira}

cuiabano, principalmente a partir da segunda metade Setecentista, tornou-se cotidiano a ação de produzir alimentos nos campos para comercializar em Vilas e Arraias. Indo, portanto, contramão à ideia da historiografia que compreendia o período colonial de Mato Grosso apenas como economia voltada ao cenário minerador.

No ano de 1791, temos o requerimento de Teodora Paes de Faria, viúva de Francisco Paes de Barros, moradora de um bairro na região de Cuiabá. Dona Teodoro possuía escravos a minerar mas, de acordo com o documento analisado, o exercício da mineração não estava mais rendendo lucros. Portanto, requerendo sesmarias para incrementar as suas rendas, a viúva solicitara terras devolutas que estão na região do Córrego Fundo. A intenção de Teodora Paes de Faria seria a criação de gado nas possíveis novas terras (REQUERIMENTO, 1791).

É sabido que a produção do ouro em Cuiabá teve seu auge nas décadas de 1720 e 1730, após essa data, a prática de minerar continuava, mas a riqueza extraída da mineração já não era a mesma (CANAVARROS, 2004). A carne bovina, ao longo de toda a época colonial, era alimento apreciado pela camada mais abastada da sociedade. A camada mais pobre, de acordo com Candido (1975), obtinha sua dieta pela caça e pesca de animais silvestres, principalmente entre os moradores das zonas rurais coloniais. A viúva de Francisco provavelmente havia percebido que a criação de gado para corte seria uma opção rentável para os seus negócios, por isso a busca pelas terras.

Outro documento que ajuda a pensar posse de terras em Mato Grosso é o requerimento de Maria da Arruda ao Governador Capitão-General João de Albuquerque de Melo Pereira e Cáceres, no ano de 1792. Maria requereu uma sesmaria herdade de seu falecido marido, Vicente de Oliveira Leme, situada na localidade de São Pedro d'El Rey. A suplicante diz que nessa localidade há uma grande fazenda de gado, da qual seus filhos herdaram. Dona Maria diz que tocou a metade do gado sozinha e, por isso, acredita ter direito a metade daqueles gados (REQUERIMENTO, 1792). A herdeira queria três léguas das sobras de sesmarias concedidas ao tenente Salvador Roiz, na paragem de Carumbé, para colocar seus gados.

Quando esta senhora se refere ter cuidado sozinha dos negócios, podemos entender que há uma protagonização da figura de Dona Maria. Ou seja, em um 


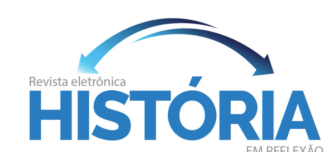

A POSSE DE TERRAS NO OESTE COLONIAL SETECENTISTA: SESMARIAS E MULHERES EM MATO GROSSO

Bruno C. Bio Augusto \& Oseias de Oliveira

período no qual a mulher da elite era idealizada como um símbolo de fragilidade, comportando-se de acordo com os códigos morais da época, uma dama, dona de terras, cuidando de gados e requerendo léguas para aumentar a sua criação vacum, era algo que extrapolava a normatividade Setecentista.

Em junho de 1793, o Procurador da Fazenda escreveu ao Rei que não havia dúvida de que a sesmaria que a suplicante requer é devoluta e que, portanto, não é prejuízo ao Real Patrimônio conceder a vontade de Dona Maria. Assim, para o Procurador: "a sesmaria que tinha o falecido marido, acha-se repartido pelos órfãos, na parte de bens que [edificaram][?], como também é certo estar devoluto o lugar que a suplicante pretende" (REQUERIMENTO, 1792).

Para Silva (2008), a concessão de sesmarias não era a única forma colonial de acesso à terra, há outras formas de ocupação como posse, compra, arrematação, dote, herança e doação. Na modalidade de herança, há a hipóteses de que sesmeiros utilizavam nomes de outras pessoas para acumular terras quando já possuíam certa quantidade.

De acordo com o requerimento de Dona Maria acima tratado, é possível entender que os filhos receberam, em herança, a terra com o gado. Pela nossa interpretação, o marido deixou a viúva fora da repartição da terra, mas a incluiu na repartição dos animais, ou, talvez, esses animais tenham sido criado após a morte de seu esposo. A certeza é que Dona Maria não recorreu da vontade de Vicente de Oliveira em deixar a terra apenas para os filhos. O que a documentação nos aponta é que a mulher afirmou ser proprietária de metade das cabeças de gados e que, para criá-las, seria preciso uma porção de terra.

Podemos compreender, pela documentação analisada, que as mulheres aparecem na ação cotidiana da administração das sesmarias. As propriedades encabeçadas por mulheres preocupadas em dar uso para as terras aparecem nas documentações e demonstram que Vila do Cuiabá foi palco de disputas acerca de alargamento de propriedades, brigas por heranças, e associações entre homens e mulheres sesmeiros.

Pelo trabalho com algumas fontes, podemos entender que ao longo de todo o século XVIII a capitania de Mato Grosso recebeu atenção da administração metropolitana. No ano de 1727, com a chegada do governador Rodrigo Cezar de 


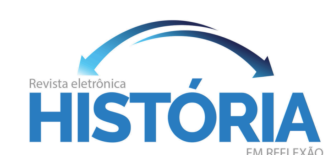

A POSSE DE TERRAS NO OESTE COLONIAL SETECENTISTA: SESMARIAS E MULHERES EM MATO GROSSO

Bruno C. Bio Augusto \& Oseias de Oliveira

Menezes, o até então arraial do Cuiabá recebeu o estatuto de Vila, contando, a partir desse evento, com as instituições da Câmara, Senado e Fórum. Até a década de 1730, Vila do Cuiabá foi o núcleo urbano mais afastado do litoral da América Portuguesa. Com o passar dos anos, foram surgindo outros povoamentos e, após o segundo quartel dos Setecentos, Vila Bela tornou também importante núcleo urbano para a capitania.

Encontramos Vila do Cuiabá e Vila Bela, e outros lugares da capitania, nos documentos acerca dos requerimentos de posses de terras, seja por arrendamento, herança, dívidas, entre outras maneiras de requerer o direito à terra. As mulheres, como trabalhado neste texto, protagonizaram a vontade, e muitas vezes efetivação, de serem donas de propriedades. A Coroa, pela política de ocupação e abastecimento interno, muitas vezes concedia as terras. Não podemos deixar de falar que, para a mulher abastada, a aquisição de sesmarias era infinitamente mais acessível que para as pobres. Mostrando-nos que não bastava apenas requerer terras, mas sim contar com influência de cabedais para legitimar suas posses.

\section{Considerações Finais}

Ocupação da terra esteve envolvido com a política de doação de sesmarias na capitania de Mato Grosso. A posse da terra esteve ligada, naquele momento, com a política de abastecimento interno da América portuguesa. A produção agrícola não respaldava apenas em um mercado monocultor exportador. Havia, para a história social rural, agricultura que abastecia internamente a população. Formando-se uma rede de negócios.

A região de Cuiabá, como estudado neste trabalho, nas duas primeiras décadas após estabelecido a Câmara Municipal, ou seja, após 1727, tornou-se importante centro de extração aurífera. Cuiabá e seus arredores, principalmente após a segunda metade do século XVIII, não está apenas associado ao trabalho nas minas. Pelos requerimentos arrolados, encontramos a preocupação de mulheres requerendo terras para plantar e/ou criar gado. Dessa forma, podemos considerar que houve, a partir dos documentos estudados, uma mão dupla entre Coroa e súditos, ou seja, a 


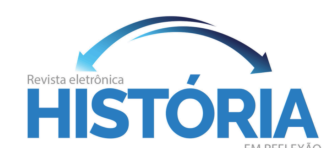

A POSSE DE TERRAS NO OESTE COLONIAL SETECENTISTA: SESMARIAS E MULHERES EM MATO GROSSO

Bruno C. Bio Augusto \& Oseias de Oliveira

Metrópole, pela concessão de posse, reforçava as fronteiras e, as pessoas, pela requisição de terras, aumentavam os seus potentados.

As donas cuiabanas trazidas neste estudo contribuem para entendermos as ações femininas de herdeiras de terras para além da imagem de mulher da elite reclusa e dócil. Dona Maria e Dona Teodora são mulheres que apreendem um cotidiano cuiabano que encabeçaram a administração de sesmarias. Mostrando-nos que na sociedade Setecentistas de Mato Grosso havia a presença de sesmeiras e suas táticas de manutenção do poder: arrendamento, associação e requerimento de herança.

\section{Fontes}

Governador -Geral Rodrigo Cesar de Menezes, 1723. DEPARTAMENTO DO INSTITUTO HISTÓRICO DE SÃO PAULO (DIHSP), 1913 p.11.

Núcleo de Documentação e Informação Histórica Regional. D. Antônio Rolim de Moura, Primeiro Conde de Azambuja; Correspondências. Cuiabá: Imprensa Universitária, 1982.

REQUERIMENTO de Maria da Arruda para o Governador e Capitão-General da Capitania de Mato Grosso João de Albuquerque de Melo Pereira e Cáceres. 1792, Dezembro, 03 Vila Bela. Referência: BR APMT.SES. RQ. 0327 Caixa n. 004.

REQUERIMENTO de Teodora Paes de Faria para o Governador Capitão-General da Capitânia de Mato Grosso João de Albuquerque de Melo Pereira e Cáceres. 1791, Julho, 16 - Vila Bela. Arquivo Público de Mato Grosso. Referência: BR APMT.SES RQ. 0305 Caixa n.004.

POMBAL, Marquês de. Sobre o methodo que se pode seguir para a cobrança dos guintos que devem pagar a S. Mag. as Minas do Brazil. Lisboa em 20 de novembro de 1750. Biblioteca Nacional de Portugal Cod. 6979.

\section{Bibliografia}

AMADO, Janaína. Região, Sertão, Nação. Revistas Estudos Históricos. Rio de Janeiro. v.9, n.15, 1995 p.145-151.

CANAVARROS, Otávio. O poder metropolitano em Cuiabá (1727 - 1752). Cuiabá/MT: EdUFMT, 2004. 


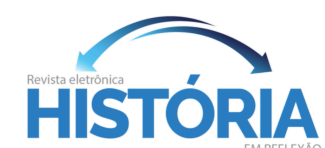

A POSSE DE TERRAS NO OESTE COLONIAL SETECENTISTA: SESMARIAS E MULHERES EM MATO GROSSO

Bruno C. Bio Augusto \& Oseias de Oliveira

CANDIDO, Antonio. Os parceiros do Rio Bonito: estudo sobre o caipira paulista e a transformação dos seus meios de vida. $3^{a}$ edição. São Paulo: Livraria Duas Cidades Itda, 1975.

CERTEAU, Michel de. Relatos de espaço. In: A invenção do cotidiano: artes de fazer. Petrópolis: editora Vozes, 1998.

A escrita da história. Rio de Janeiro: Forense Universitária, 1982.

FRAGOSO, João et al. A economia colonial brasileira: (séculos XVI - XIX). São Paulo: Atual, 1998.

GOMES, Marília Aparecida da Silva. Produção Agrícola e práticas alimentares na fronteira oeste: Vila Bela da Santíssima Trindade (1752-1790). Dissertação de mestrado. Programa de Pós-Graduação em História. Universidade Federal de Mato Grosso. Cuiabá-MT, 2008.

LEFEBVRE, Henry. La production de l'espace. 4eéd. Paris: Éditions Anthropos, 2000.

LINHARES, Maria Yedda; DA SILVA, Francisco Carlos Teixeira. História da agricultura brasileira: combates e controvérsias. São Paulo: Brasiliense, 1981.

JESUS, Nauk Maria de. Saúde e doença: práticas de cura no centro da América do Sul (127-1808). Dissertação de Mestrado. Programa de Pós-Graduação em História. Universidade Federal de Mato Grosso, Cuiabá, 2001.

MARTINS, José de Souza. Fronteira: a degradação do outro nos confins do humano. São Paulo: Hucitec, 1997.

MORAES, Benone da Silva Lopes. Dilatar limites: a a Ideia Geral de Luis de Albuquerque (1772-1781). Dissertação de Mestrado. Programa de Pós-Graduação em História. Universidade Federal de Mato Grosso. Cuiabá-MT, 2011.

MOTTA, Márcia Maria Menendes. O rural à lá gauche: campesinato e latifúndio nas interpretações de esquerda (1955-1996). Niterói: Editora da UFF, 2014.

OLIVEIRA, Tiago Kramer de. Ruralidade na terra da conquista: ambientes rurais lusoamericanos no centro da América do Sul (1716-1750). Dissertação de mestrado. Programa de Pós-Graduação em História. Universidade Federal de Mato Grosso. Cuiabá-MT, 2008.

PERROT, Michelle. As mulheres ou os silêncios da história. Bauru, SP: Edusc, 2005. 


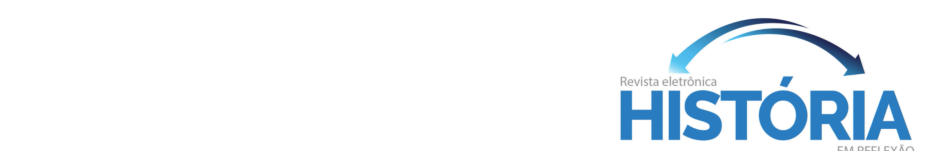

A POSSE DE TERRAS NO OESTE COLONIAL SETECENTISTA: SESMARIAS E MULHERES EM MATO GROSSO

Bruno C. Bio Augusto \& Oseias de Oliveira

Artigo recebido em 23/04/2018

Artigo aceito em 25/06/2018 